\title{
Haemodynamic response to dynamic exercise after heart-lung transplantation
}

\author{
J-L. Vachiéry*, G. Niset*, M. Antoine**, J-L. LeClerc**, S. Degré*, M. Estenne***
}

\begin{abstract}
Haemodynamic response to dynamic exercise after heart-lung transplantation. J-L. Vachiéry, G. Niset, M. Antoine, J-L. LeClerc, S. Degré, M. Estenne. (C) ERS Journals Ltd 1999. ABSTRACT: The purpose of this study was to investigate the haemodynamic response to dynamic exercise after heart-lung transplantation (HLT).

Nine stable HLT recipients (6 males) were studied 12-55 months after transplantation. While sitting on a cycle ergometer, they first underwent a maximal symptomlimited exercise test (power increment was $10 \mathrm{~W} \cdot \mathrm{min}^{-1}$ ) to determine the maximal tolerable workload. On the next day, they performed a second exercise test at $0,40,60$ and $80 \%$ of their predetermined maximal workload (mean \pm SD: $108 \pm 20 \mathrm{~W}$ ). Stage duration was 6 min. Respiratory, gas exchange, and haemodynamic measurements were performed at rest, during the last minute of each stage, and after recovery.

Haemodynamic variables at rest were within normal limits except heart rate (HR) which was greater and stroke volume index (SVI) which was lower than normal. Peak oxygen consumption was $61 \pm 8 \%$ of predicted. HR showed an initial slow increase followed by a steeper rise, and a delayed return to baseline during the recovery period. SVI and cardiac index (CI) increased at the onset of exercise but did not change significantly at $40-80 \%$ of the maximal workload. Pulmonary capillary wedge pressure increased from $4 \pm 2 \mathrm{mmHg}$ at rest to $14 \pm 3 \mathrm{mmHg}$ at maximal exercise.

It is concluded that during dynamic exercise, heart-lung transplantation recipients demonstrate a chronotropic incompetence, a reduced increase in cardiac index and stroke volume index, and an excessive rise in left ventricular filling pressures. These alterations may contribute to the persistent exercise limitation.

Eur Respir J 1999; 14: 1131-1135.
\end{abstract}

Heart-lung transplantation (HLT) has become an accepted therapeutic option for selected patients with end-stage cardiorespiratory diseases [1]. Most HLT patients experience a marked improvement in exercise tolerance after surgery [2], but their maximal exercise capacity remains reduced with values of peak oxygen uptake $\left(V^{\prime} \mathrm{O}_{2}, \mathrm{p}\right)$ ranging $39-60 \%$ of predicted [2-7]. Although it is generally accepted that this exercise limitation primarily originates in peripheral muscle dysfunction [8], an inadequate cardiac response might also be at work. Indeed, previous studies in heart transplant recipients have demonstrated an abnormal adaptation of the graft to exercise with an insufficient rise in cardiac output and an abnormal increase in left ventricular filling pressures [5, 9-12], due to a combination of chronotropic incompetence and diastolic dysfunction. Although the pathogenesis of this dysfunction is not fully understood, cardiac rejection is considered to be a likely contributor [9-12].

Because acute and chronic rejection of the heart is uncommon after HLT [13], it would be expected that diastolic dysfunction would be less pronounced and hence cardiac adaptation to exercise be better preserved after HLT than after heart transplantation (HT). There are, however, no studies of which the authors are aware, that report invasive haemodynamic measurements during exercise in HLT recipients. It was therefore decided to perform such measurements in a group of stable patients with HLT. Departments of $*$ Cardiology, $* *$ Cardiac
Surgery, and $* * *$ Chest Medicine, Erasme University Hospital, Brussels, Belgium.

Correspondence: J-L. Vachiéry

Department of Cardiology

Hôpital Erasme

808 Route de Lennik

1070 Brussels

Belgium

Fax: 3225556652

Keywords: Exercise testing haemodynamics

heart-lung transplantation

Received: November 251998

Accepted after revision July 211999

J.L. Vachiéry is a fellow of the Foundation pour la Chirurgie Cardiaque that supported the acquisition of the Medicalgraphics exercise system.

Methods

Study population

Nine consecutive HLT recipients (6 males) who were hospitalized for their annual evaluation were asked to enter the study. The conditions requested for inclusion were: 1) a stable clinical condition for a period of at least 3 months prior to the study; 2) the absence of bronchiolitis obliterans syndrome [14]; and 3) the patients' willingness to have an invasive haemodynamic study for research purposes. Exercise tolerance was not an inclusion criterion. On average, the patients were (mean \pm SD) $40 \pm 7$ yrs of age. They were studied $33 \pm 15$ months (range 12-55 months) after HLT which had been performed for primary pulmonary hypertension (4 patients), cystic fibrosis (3 patients), $\alpha_{1}$-antitrypsin deficiency (1 patient), and coal miners pneumoconiosis (1 patient).

All patients had been involved in a postoperative rehabilitation programme up to the sixth postoperative month, but they were sedentary at the time of studies. The patients' chest radiographs and standard pulmonary function tests were within normal limits, except for a slight reduction in carbon monoxide diffusing capacity which averaged $78.5 \%$ of predicted after adjustment for haemoglobin concentration [15]. Their electrocardiogram, echocardiogram, and radionuclide ejection fraction were all consistent with a normal systolic function of the allograft. 
The left ventricular ejection fraction averaged $61.8 \pm 5.3 \%$. Pulmonary infection and rejection were excluded by bronchoalveolar lavage and transbronchial lung biopsies performed $72 \mathrm{~h}$ before the exercise test. Immunosuppression consisted of a conventional triple regimen including cyclosporine, azathioprine, and steroids. Six patients were treated for systemic hypertension, 4 with a calciumchannel blocker or an angiotensin converting enzyme inhibitor and 2 with a combination of both agents; these drugs are not considered to have any detrimental effect on myocardium contractility. No patient was treated with a $\beta$-adrenergic blocking drug nor received a medication likely to modify heart rate. Renal function was only mildly impaired (serum creatinine $1.7 \pm 0.8 \mathrm{mg} \cdot \mathrm{dL}^{-1}$ ) and mean haemoglobin was close to normal values $(11.9 \pm 1.2$ $\left.\mathrm{g} \cdot \mathrm{dL}^{-1}\right)$.

\section{Study design}

The study protocol received approval by the local ethics committee and all patients gave informed consent. Two incremental exercise tests were performed on separate days with the subject seated on an electrically braked cycle ergometer and pedalling at a frequency of 50 revolutions per minute (rpm). All patients began the tests with unloaded pedalling. During the first test, the power output increased by $10 \mathrm{~W}$ each minute, until exhaustion (inability to maintain a constant speed).

On the next day, a routine right ventricular endomyocardial biopsy was performed via the right internal jugular vein. A 7F balloon-tipped thermodilution Swan Ganz catheter (Baxter-American Edwards; Critical Labs division, Irvine, CA, USA) was then positioned in a branch of the right pulmonary artery and a small plastic cannula was inserted into the radial artery under local anaesthesia. After a $30 \mathrm{~min}$ rest, the patients were transported to the exercise laboratory where the second exercise test was performed. For this test the workload was adjusted to correspond to 0 , 40,60 and $80 \%$ of the maximal workload determined for each individual on the previous day (on average, $108 \pm 20$ $\mathrm{W})$, and stage duration was $6 \mathrm{~min}$. Haemodynamic and respiratory variables were recorded in the upright position at rest, during the last minute of each stage, and after $6 \mathrm{~min}$ of recovery. Arterial and venous blood were sampled at similar time intervals and were immediately stored in ice.

\section{Respiratory measurements}

Breath-by-breath analysis of ventilation and mixed expired gas concentrations were obtained with an open-circuit technique (Cardiopulmonary Exercise System CPX/D MedGraphics, St. Paul, MN, USA, calibrated before each exercise test. Oxygen consumption $\left(V^{\prime} \mathrm{O}_{2}\right)$, carbon dioxide production $\left(V^{\prime} \mathrm{CO}_{2}\right)$ and minute ventilation $\left(V^{\prime} \mathrm{E}\right)$ were averaged every $15 \mathrm{~s}$ and respiratory exchange ratio (RER) was calculated from $V^{\prime} \mathrm{O}_{2}$ and $V^{\prime} \mathrm{CO}_{2}$ values. Standard formulas were used to calculate predicted values for $V^{\prime} \mathrm{O}_{2}$,p in each patient, according to sex, age, height, and body weight [16]. Maximal voluntary ventilation (MVV) was calculated as forced expiratory volume in one second (FEV1) $\times 40[16]$.

\section{Haemodynamic measurements and blood gas analysis}

Systemic and pulmonary artery pressures were continuously monitored with a Siemens monitoring system (Siemens Sirflust 404; Siemens, Germany) and heart rate (HR) was recorded using a three-lead electrocardiogram. The pressure transducers were zero referenced at midchest and vascular pressures measured at end-expiration. During the last minute of each stage, the following variables were recorded on a Hewlett Packard strip-chart recorder at a paper speed of $25 \mathrm{~mm} \cdot \mathrm{s}^{-1}$ : HR; systolic (PAPs), diastolic (PAPd) and mean (PAPm) pulmonary artery pressure; right atrial pressure (RAP); pulmonary artery wedge pressure (PCWP); systolic (SAPs), diastolic (SAPd) and mean (SAPm) systemic artery pressure. Arterial and mixed venous blood samples were analysed with a Radiometer Blood Gas Analyser for partial pressure of oxygen $\left(\mathrm{Pa}_{\mathrm{a}} \mathrm{O}_{2}\right)$ and carbon dioxide $\left(\mathrm{Pa}_{\mathrm{a}}, \mathrm{CO}_{2}\right)$, and for $\mathrm{pH}$ determination. Oxygen content was measured with a Instruments Laboratory Oxymeter. Cardiac output (CO) was calculated using the Fick method, and stroke volume (SV), systemic (SVR) and pulmonary (PVR) vascular resistance were calculated from standard formulas and indexed to body surface area. Arterial serum lactate was determined with a Hitachi 911 analyser.

\section{Statistical analysis}

Data analysis was limited to measurements obtained during the second exercise test. Respiratory and haemodynamic variables measured during the last minute of each stage were used for analysis and are reported as mean $\pm \mathrm{SD}$. The effects of exercise were evaluated using a repeated measure ANOVA. A p-value of $<0.05$ was considered to be statistically significant.

\section{Results}

\section{Baseline resting values}

Resting respiratory, gas exchange, and haemodynamic variables are reported in tables 1 and 2. The subjects slightly hyperventilated at rest, as evidenced by the low $P \mathrm{a}, \mathrm{CO}_{2}$. HR was greater and $\mathrm{SV}$ index (SVI) was lower than reported in three previous studies involving 59 normal subjects with an average age similar to that of the current patients $[10,17,18]$, and SAPm was slightly above normal values. All other measurements were within normal limits and the endomyocardial biopsies did not reveal any pathologic feature.

\section{Respiratory and gas exchange responses to exercise}

As shown in table $1, V^{\prime} \mathrm{O}_{2}, V^{\prime} \mathrm{CO}_{2}, V^{\prime} \mathrm{E}$, and RER increased with each exercise stage. Peak $V^{\prime} \mathrm{O}_{2}$ averaged $1,312 \pm 237 \mathrm{~mL} \cdot \mathrm{min}^{-1}\left(21 \pm 3 \mathrm{~mL} \cdot \mathrm{kg}\right.$ body weight $\left.{ }^{-1} \cdot \mathrm{min}^{-1}\right)$ which represented $61 \pm 8 \%$ of predicted. All subjects stopped exercise because of leg fatigue. Peak values for $V^{\prime} \mathrm{E} /$ MVV and RER averaged $52 \pm 3 \%$ and $1.12 \pm 0.1$, respectively. $P \mathrm{a}, \mathrm{O}_{2}$ remained normal throughout the test while $P \mathrm{a}, \mathrm{CO}_{2}$ progressively decreased; this decrease accompanied a rise in plasma lactate level which was significant from $40 \%$ of the predetermined maximal workload onward. 
Table 1. - Respiratory variables at rest, at $0,40,60$ and $80 \%$ of the predetermined maximal workload, and during recovery $(\operatorname{Rec})$

\begin{tabular}{|c|c|c|c|c|c|c|}
\hline & Rest & $0 \%$ & $40 \%$ & $60 \%$ & $80 \%$ & $\operatorname{Rec}$ \\
\hline$V^{\prime} \mathrm{O}_{2} \mathrm{~mL} \cdot \mathrm{min}^{-1}$ & $307 \pm 107$ & $533 \pm 84 * * *$ & $812 \pm 139 * * *$ & $1063 \pm 166 * * *$ & $1312 \pm 237 * * *$ & $385 \pm 131 * * *$ \\
\hline$V^{\prime} \mathrm{CO}_{2} \mathrm{~mL} \cdot \mathrm{min}^{-1}$ & $222 \pm 62$ & $459 \pm 59 * * *$ & $757 \pm 112 * * *$ & $1100 \pm 177 * * *$ & $1453 \pm 286^{* * *}$ & $356 \pm 124 * * *, \#$ \\
\hline$V^{\prime} \mathrm{E} \mathrm{L} \cdot \mathrm{min}^{-1}$ & $11 \pm 3$ & $17 \pm 3 *$ & $27 \pm 5 * *$ & $39 \pm 8 * * *$ & $60 \pm 13 * * *$ & $17 \pm 6 * * *$ \\
\hline RER & $0.88 \pm 0.06$ & $0.92 \pm 0.10$ & $0.96 \pm 0.06$ & $1.04 \pm 0.07 * *$ & $1.12 \pm 0.10^{* *}$ & $0.93 \pm 0.09 * * *, \#$ \\
\hline $\mathrm{pH}$ & $7.42 \pm 0.03$ & $7.40 \pm 0.03$ & $7.39 \pm 0.04$ & $7.38 \pm 0.04$ & $73.35 \pm 0.05^{*}$ & $7.31 \pm 0.07 * *$,\#\# \\
\hline $\mathrm{Pa}_{\mathrm{a}} \mathrm{O}_{2} \mathrm{mmHg}$ & $111 \pm 12$ & $105 \pm 11 *$ & $106 \pm 11$ & $110 \pm 11$ & $106 \pm 12$ & $109 \pm 9$ \\
\hline $\mathrm{Pa}, \mathrm{CO}_{2} \mathrm{mmHg}$ & $34 \pm 6$ & $36 \pm 3$ & $35 \pm 3$ & $33 \pm 4 *$ & $29 \pm 4 * * *$ & $29 \pm 4^{\# \#}$ \\
\hline $\mathrm{AVO}_{2} \mathrm{D}$ volume $\%$ & $5.3 \pm 1.6$ & $8 \pm 1.4 * *$ & $9.7 \pm 3.6$ & $8.9 \pm 2.8$ & $11.4 \pm 1.6^{* *}$ & $6.1 \pm 1.5 * * *$ \\
\hline
\end{tabular}

Data are presented as mean $\pm \mathrm{SD}$. $V^{\prime} \mathrm{O}_{2}$ : oxygen consumption; $V^{\prime} \mathrm{CO}_{2}$ : carbon dioxide production; $V^{\prime} \mathrm{E}$ : minute ventilation; RER: respiratory exchange ratio; $\mathrm{pH}$ : arterial $\mathrm{pH} ; \mathrm{Pa}, \mathrm{O}_{2}$ : arterial partial pressure of oxygen; $\mathrm{Pa}_{\mathrm{a}} \mathrm{CO}_{2}$ : arterial partial pressure of carbon dioxide; $\mathrm{AVO}_{2} \mathrm{D}$ : arteriovenous oxygen difference. ${ }^{*}: \mathrm{p}<0.05 ; * *: \mathrm{p}<0.01 ; * * *: \mathrm{p}<0.001$, compared with previous stage; ${ }^{\#}: \mathrm{p}<0.05 ;{ }^{\# \#}: \mathrm{p}<0.001$, between rest and significance. $1 \mathrm{mmHg}=0.133 \mathrm{kPa}$.

\section{Haemodynamic response to exercise}

Results of haemodynamic measurements are summarized in table 2 and illustrated in figure 1. HR showed an initial slow increase followed by a steeper rise during the last two stages, and at the end of the recovery period it was still significantly greater than at rest. SVI increased at the beginning of exercise but plateaued at $40-80 \%$ of the predetermined maximal workload. Similarly, whereas cardiac index (CI) increased by $75 \%$ between rest and $40 \%$ of the maximal workload, it increased by only $23 \%$ during the last two stages, which did not reach statistical significance. PAPm and PCWP increased from $11 \pm 2$ and $4 \pm 1 \mathrm{mmHg}$ at rest to $27 \pm 6$ and $14 \pm 3 \mathrm{mmHg}$ at the end of exercise $(\mathrm{p}<0.001)$. Corresponding values for RAP were $4 \pm 2 \mathrm{mmHg}$ and $8 \pm 3 \mathrm{mmHg}$, respectively. SAPm increased only slightly and nonsignificantly during exercise but systemic vascular resistance decreased markedly.

\section{Discussion}

This study confirms that maximal exercise capacity remains limited after HLT. The peak $V^{\prime} \mathrm{O}_{2}$ achieved by the subjects was $61 \%$ of predicted, which compares well with previous studies [2-4] [19]. As recently recommended [20], an exercise protocol was used that had stages of long duration because this allows more time for physiological adaptation and achievement of a haemodynamically stable steady state in patients with a denervated heart (see below). As a result, the patients achieved higher HR and lower RER at maximal exercise than previously reported in HLT recipients [3-6].

The pattern of HR response observed in this study, i.e., an elevated resting HR, an initial slow increase followed by a steeper rise during exercise, and a delayed return to baseline during the recovery period, is similar in all respects to that seen after HT [3-6, 9-12] and is consistent with the response of a denervated heart. Although it has been suggested that reinnervation may occur over time after HT [21, 22], this is not supported by a recent report on the evolution of the HR response to exercise up to 60 months after surgery [23]. These and the present data are thus consistent with the absence of functional reinnervation of the cardiac allograft after HT and HLT.

In contrast to HR, SVI showed changes that were qualitatively comparable to those seen in normal individuals with a marked increase at the beginning of exercise followed by a plateau. Absolute values of SVI, however, were below normal both at rest and at maximal exercise $[10,17,18]$, as a result, CI only doubled from the resting value and this change occurred primarily in the early phase of exercise (fig. 1). Furthermore, PCWP showed a brisk elevation and increased to a maximal value of $14 \mathrm{mmHg}$. These findings contrast with the haemodynamic response of upright normal subjects who show a linear increase in

Table 2. - Haemodynamic variables at rest, at $0,40,60,80 \%$ of the predetermined maximal workload, and during recovery $(\operatorname{Rec})$

\begin{tabular}{|c|c|c|c|c|c|c|}
\hline & Rest & $0 \%$ & $40 \%$ & $60 \%$ & $80 \%$ & Rec \\
\hline HR bpm & $106 \pm 12$ & $111 \pm 11 *$ & $119 \pm 12 * *$ & $133 \pm 11 * * *$ & $151 \pm 14^{* * *}$ & $126 \pm 10 * * *$,\#\#\# \\
\hline $\mathrm{SAPm} \mathrm{mmHg}$ & $112 \pm 6$ & $115 \pm 10$ & $114 \pm 8$ & $119 \pm 9$ & $121 \pm 18$ & $101 \pm 8 * * *, \#$ \\
\hline PAPm mmHg & $11 \pm 2$ & $16 \pm 3 * * *$ & $18 \pm 3 *$ & $22 \pm 3 * *$ & $27 \pm 6 * * *$ & $12 \pm 5 * * *$ \\
\hline PCWP mmHg & $4 \pm 2$ & $5 \pm 2 * *$ & $7 \pm 2 * *$ & $9 \pm 2 * * *$ & $14 \pm 3 * * *$ & $4 \pm 1 * * *$ \\
\hline RAP mmHg & $4 \pm 2$ & $4 \pm 2$ & $6 \pm 2 * *$ & $6 \pm 2$ & $8 \pm 3 * * *$ & $3 \pm 2 * * *$ \\
\hline $\mathrm{CI} \mathrm{L} \cdot \mathrm{min}^{-1} \cdot \mathrm{m}^{-2}$ & $3.2 \pm 1$ & $4 \pm 0.9^{*}$ & $5.6 \pm 1.3 * * *$ & $6.2 \pm 1.5$ & $6.9 \pm 1.5$ & $4.1 \pm 1.7 * * *, \#$ \\
\hline $\mathrm{SVI} \mathrm{mL} \cdot \mathrm{m}^{-2}$ & $31 \pm 12$ & $37 \pm 10$ & $47 \pm 15 * *$ & $47 \pm 14$ & $46 \pm 12$ & $33 \pm 16 * * *$ \\
\hline PVRI Wood units $\cdot \mathrm{m}^{-2}$ & $2.5 \pm 1.1$ & $2.6 \pm 0.7$ & $2.1 \pm 0.5$ & $2.1 \pm 0.7$ & $1.9 \pm 0.7$ & $2.7 \pm 1.6^{*}$ \\
\hline SVRI Wood units $\cdot \mathrm{m}^{-2}$ & $39 \pm 19$ & $29 \pm 8^{*}$ & $21 \pm 6^{*}$ & $19 \pm 5$ & $17 \pm 4$ & $30 \pm 14^{*, \#}$ \\
\hline Lactate $\mathrm{mEq} \cdot \mathrm{L}^{-1}$ & $1.0 \pm 0.5$ & $1.5 \pm 0.6$ & $2.7 \pm 0.8 * *$ & $5.1 \pm 2 * * *$ & $8.1 \pm 0.9 * * *$ & $7.5 \pm 1.6^{*, \# \# \#}$ \\
\hline
\end{tabular}

Data are presented as mean \pm SD. HR: heart rate; bpm: beats per minute; SAPm: mean systemic arterial pressure; PAPm: mean pulmonary artery pressure; PCWP: pulmonary artery wedge pressure; RAP: right atrial pressure; CI: cardiac index; SVI: stroke volume index; PVRI: pulmonary vascular resistance; SVRI: systemic vascular resistance; Lactate: plasma lactate level. *: $\mathrm{p}<0.05 ; * *: \mathrm{p}<0.01 ; * * *$ : $\mathrm{p}<0.001$, compared with previous stage; ${ }^{\#}: \mathrm{p}<0.05{ }^{\# \# \#}: \mathrm{p}<0.001$, between rest and significance. $1 \mathrm{mmHg}=0.133 \mathrm{kPa}$.. 

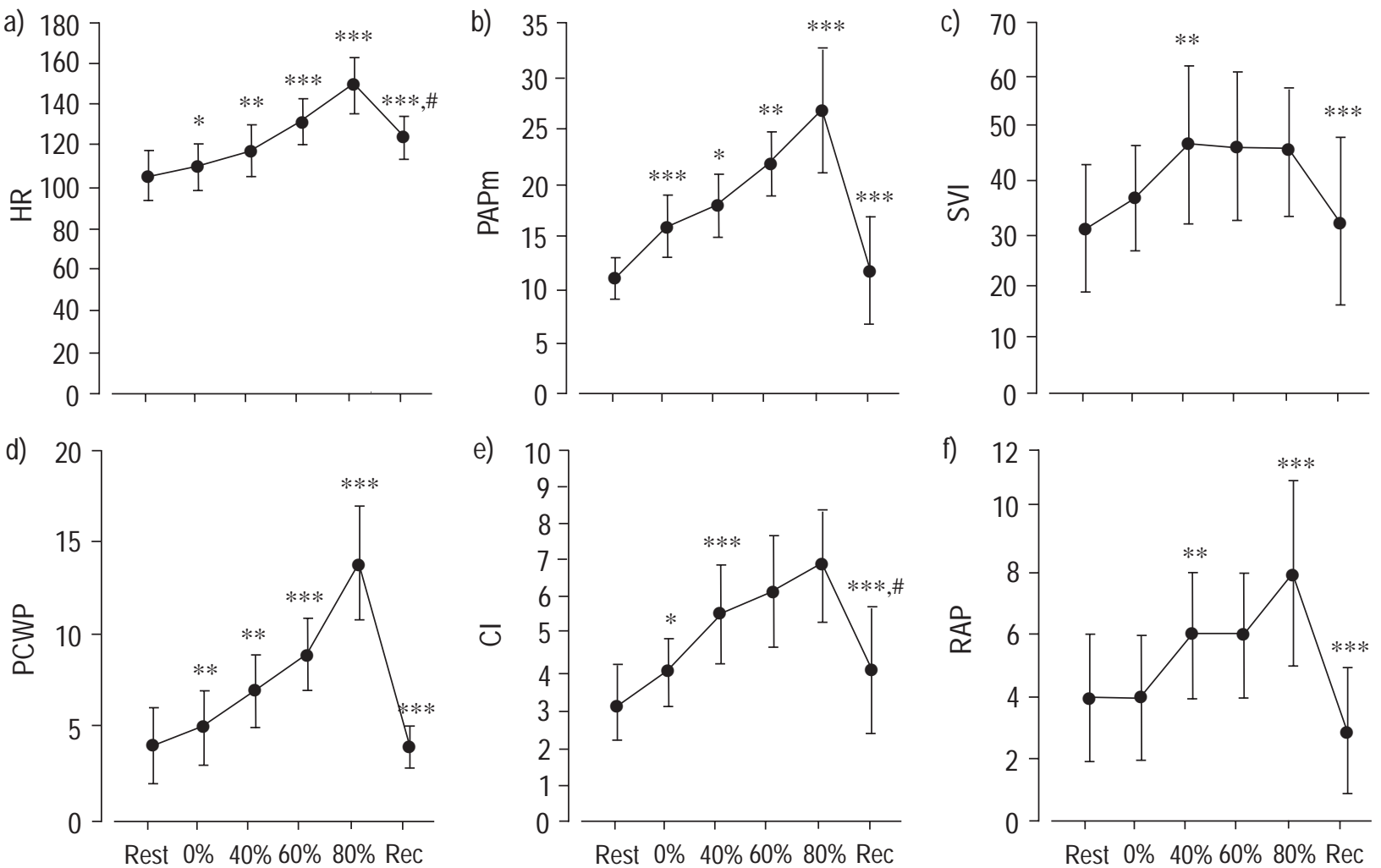

Fig. 1. - Results of the haemodynamic measurements. a) Heart rate (HR); b) mean pulmonary artery pressure (PAPm); c) stroke volume index (SVI); d) pulmonary artery wedge pressure (PCWP); e) cardiac index (CI); f) right atrial pressure (RAP), at rest, during exercise $(0,40,60$ and $80 \%$ of predetermined maximal workload), and during recovery $(\operatorname{Rec}){ }^{*}: \mathrm{p}<0.05 ; * *: \mathrm{p}<0.01 ; * * *: \mathrm{p}<0.001$, compared to preceding stage. ${ }^{\#}$ : $\mathrm{p}<0.05$, between rest and recovery.

CI throughout exercise and values of PCWP that do not exceed $10 \mathrm{mmHg}[10,17,18]$.

Very similar haemodynamic alterations have been reported in HT recipients $[9,10,24]$ and have been attributed, at least in part, to an impairment of diastolic function due to left ventricular myocardial stiffness and incoordinate contraction and relaxation $[10,12,24]$. Although the authors did not specifically assess diastolic function in this study, it is tempting to speculate that the altered haemodynamic response to exercise after HLT is also related to a combination of chronotropic incompetence and diastolic dysfunction. Because the patients did not have evidence of acute or chronic rejection, this would imply that this dysfunction may be triggered by other mechanisms such as myocardial injury related to cold preservation, cyclosporine-induced myocardial fibrosis, denervation, and systemic hypertension [9-12, 24]. Diastolic function after HLT has only been assessed in a single study performed in a small group of patients and no significant abnormality was demonstrated [24]. These patients, however, were studied at rest during the first year after surgery whereas the current patients were studied during exercise on average 33 months after transplantation, which makes comparison between studies difficult.

Although the haemodynamic abnormalities observed here probably contributed to the reduction in exercise capacity, several studies have demonstrated that peripheral muscle weakness makes an important contribution to the exercise limitation seen after HLT and lung transplantation $[2,8,25-28]$. Factors responsible for this muscle dysfunc- tion may include pretransplant deconditioning, chronic steroid intake, cyclosporin-induced mitochondrial myopathy, and muscle wasting, in particular in patients with cystic fibrosis $[2,19,26,27]$. Peripheral muscle dysfunction may also account for the early anaerobiosis and the associated hyperventilation which were observed in the current patients. However, other mechanisms such as pulmonary denervation [6], subtle alterations in ventilation-perfusion matching $[2,3]$, and patient's instrumentation [3] may also contribute to the observed increase in both resting and exercise ventilation [3-7].

In summary, the haemodynamic response to exercise in heart-lung transplant recipients is characterized by a chronotropic incompetence, a reduced increase in stroke volume index and cardiac index and an excessive rise in left ventricular filling pressures. These haemodynamic abnormalities, together with alterations in peripheral muscle function, may contribute to the persistent exercise limitation after heart lung transplant.

\section{References}

1. Hosenpud J, Bennet LE, Keck BM, Fiol B, Novick RJ. The registry of the International Society for Heart and Lung Transplantation: fourteenth official report. J Heart Lung Transplant 1997; 16: 691-712.

2. Schwaiblmair M, Reichenspurner $\mathrm{H}$, Müller $\mathrm{C}$, et al. Cardiopulmonary exercise testing before and after lung and heart-lung transplantation. Am J Respir Crit Care Med 1999; 159: 1277-1283. 
3. Theodore J, Morris A, Burke CM, et al. Cardiopulmonary function at maximum tolerable constant work rate exercise following human heart-lung transplantation. Chest 1987; 92: 433-439.

4. Sciurba FC, Owens GR, Sanders MH, et al. Evidence of an altered pattern of breathing during exercise in recipients of heart-lung transplants. N Engl J Med 1988; 319: 1186-1192.

5. Banner N, Lloyd MH, Hamilton RD, Innes JA, Guz A, Yacoub M. Cardiopulmonary response to dynamic exercise after heart and combined heart-lung transplantation. Br Heart J 1989; 61: 215-223.

6. Kimoff RJ, Cheong TH, Cosio M, Guerraty A, Levy RD. Pulmonary denervation in humans. Effects on dyspnea and ventilatory pattern during exercise. Am Rev Respir Dis 1990; 142: 1034-1040.

7. Estenne M, Primo G, Yernault JC. Cardiorespiratory responses to dynamic exercise after human heart-lung transplantation. Thorax 1987; 629-630.

8. Lands LC, Smountas AA, Mesiano G, et al. Maximal exercise capacity and peripheral skeletal muscle function after lung transplantation. J Heart Lung Transplant 1999; 18: 113-120.

9. Rudas L, Pflugfelder PW, McKenzie N, Menkis A, Novick RJ, Kostuk WJ. Normalization of upright exercise hemodynamics and improved exercise capacity one year after orthotopic cardiac transplantation. Am J Cardiol 1992; 69: 1336-1339.

10. Kao AC, Van Trigt P III, Shaeffer-McCall GS, et al. Central and peripheral limitations to upright exercise in untrained cardiac transplant recipients. Circulation 1994; 89: 2605-2615.

11. Kavanagh $\mathrm{T}$, Yacoub M, Mertens DJ, Kennedy J, Campbell RB, Sawyer P. Cardiorespiratory responses to exercise training after orthotopic cardiac transplantation. Circulation 1988; 77: 162-171.

12. Paulus WJ, Bronswaer JGF, Felice H, Kishan N, Wellens F. Deficient acceleration of left ventricular relaxation during exercise after heart transplantation. Circulation 1992; 86: 1175-1185.

13. Lim TT, Botas J, Ross H, et al. Are heart-lung transplant recipients protected from developing transplant coronary artery disease? Circulation 1996; 94: 1573-1577.

14. International Society for Heart and lung Transplantation. A working formulation for the standardization of nomenclature and for clinical staging of chronic dysfunction in lung allografts. J Heart Lung Transplant 1993; 12: 713-716.

15. Marrades RM, Diaz O, Roca J, et al. Adjustment of DLCO for hemoglobin concentration. Am J Respir Crit Care Med 1997; 155: 236-241.
16. Wasserman K. Principles of exercise testing and interpretation. Chapter 6: Normal values. 2nd edn. Philadelphia, Lea and Febiger, 1994; 96, 113.

17. Higginbotham MB, Morris KG, Williams RS, McHale PA, Coleman RE, Cobb FR. Regulation of stroke volume during submaximal and maximal upright exercise in normal man. Circ Res 1986; 58: 281-291.

18. Thadani U, Parker JO. Hemodynamics at rest and during supine and sitting bicycle exercise in normal subjects. $\mathrm{Am}$ J Cardiol 1978; 41: 52-59.

19. Levy RD, Ernst P, Levine SM, et al. Exercise performance after lung transplantation. $J$ Heart Lung Transplant 1993; 12: 27-33.

20. Gullestad L, Myers J, Noddeland H, et al. Influence of the exercise protocol on hemodynamic, gas exchanges and neurohumoral responses to exercise in heart transplant recipients. J Heart Lung Transplant 1996; 15: 304313.

21. Wilson RF, Laxson DD, Christensen BV, McGinn AL, Kubo SH. Regional differences in sympathetic reinnervation after human orthotopic cardiac transplantation. Circulation 1993; 88: 165-171.

22. Kaye DM, Esler M, Kingwell B, McPherson G, Esmore D, Jennings G. Functional and neurochemical evidence for partial cardiac sympathetic reinnervation after cardiac transplantation in humans. Circulation 1993; 88: 1110 1118.

23. Mandak JS, Aaronson KD, Mancini DM. Serial assessment of exercise capacity after heart Transplantation. $J$ Heart Lung Transplant 1995; 14: 468-478.

24. Hausdorf G, Banner N, Mitchell A, Khagani A, Martin M, Yacoub M. Diastolic function after cardiac and heartlung transplantation. Br Heart J 1989; 62: 123-132.

25. Ambrosino N, Bruschi C, Callegari G, et al. Time course of exercise capacity, skeletal and respiratory muscle performance after heart-lung transplantation. Eur Respir $J$ 1996; 9: 1508-1514.

26. Tirdel GB, Girgis R, Fishman RS, Theodore J. Metabolic myopathy as a cause of the exercise limitation in lung transplant recipients. J Heart Lung Transplant 1998; 17 : 1231-1237.

27. Evans AB, Al-Himyary AJ, Hrovat MI, et al. Abnormal skeletal muscle oxidative capacity after lung transplantation by 3 IP-MRS. Am J Respir Crit Care Med 1997; 155: 615-621.

28. Hall MJ, Snell GI, Side EA, Esmore DS, Walters EH, Williams TJ. Exercise, potassium, and muscle deconditioning post-thoracic organ transplantation. J Appl Physiol 1994; 77: 2784-2790. 